Article

\title{
What Determines Behaviours Towards Water Resources Management in a Rural Context? Results of a Quantitative Study
}

\author{
Murat Okumah $^{1, * \mathbb{D}}$, Ata Senior Yeboah ${ }^{2}{ }^{\mathbb{D}}$, Elias Nkiaka $^{1}$ and Richard Apatewen Azerigyik ${ }^{2}$ \\ 1 Sustainability Research Institute, University of Leeds, Leeds LS2 9JT, UK; e.nkiaka@leeds.ac.uk \\ 2 Department of Planning, Kwame Nkrumah University of Science and Technology, Kumasi, Ghana; \\ ata.yeboah@yahoo.com (A.S.Y.); azerigyikrichard@gmail.com (R.A.A.) \\ * Correspondence: ee15sa@leeds.ac.uk
}

Received: 27 May 2019; Accepted: 10 June 2019; Published: 11 June 2019

\begin{abstract}
Recent environmental policies introduced to safeguard the quality of water resources have focussed on encouraging pro-environmental behaviours (PEB). This has resulted in a considerable volume of research output that seeks to investigate the determinants of PEB in the context of water resources management. However, there is a paucity of literature exploring the topic within the developing country context, though evidence suggests that these regions record the highest rates of water resource pollution. This limits our understanding of the determinants of PEB and thus constrains our ability to develop and implement effective policies to encourage uptake of PEB. Following this, we apply the Theory of Planned Behaviour to explore the determinants of PEB, using structural equation modelling to analyse survey data from rural Ghana. The evidence supports the hypothesis that attitudes and perceived behavioural control affects intentions, and this translates into pro-environmental behaviour. Results further indicate that attitude and perceived behavioural control have a strong explanatory power in people's intentions, and intentions are influential drivers of pro-environmental behaviour. An explicit recognition of the role of situational factors could offer a profound understanding of the determinants of behaviours that promote water resources management and support the development and implementation of policies aimed at safeguarding the quality of water resources.
\end{abstract}

Keywords: water resources management; river; pro-environmental behaviour; environmental attitudes; structural equation modelling; Ghana

\section{Introduction}

Water resources (e.g., lakes, rivers and streams) contribute significantly to the agricultural, industrial, domestic, transportation and tourism sectors [1]. Recent reports indicate a deteriorating state of water resources, attributable to a number of factors including diffuse pollution from agriculture, sewage treatment plants and household waste [2-4]. Following the wide recognition that pollution of water resources is human induced, recent environmental policies have thus focused on understanding and influencing human behaviour as a strategy to safeguard the quality of water resources $[5,6]$.

Understanding and influencing people's behaviour is challenging due to the complexities associated with pro-environmental behaviour and actions that result in environmental management gains or at worst cause no harm to the environment [5]. This has resulted in a considerable volume of research output that seeks to investigate the determinants of pro-environmental behaviour in the context of land and water resources management, e.g., [7-14]. These studies highlight the role of various factors such as awareness, attitudes, ascription of responsibility and situational factors, among 
others. However, they mostly employ either qualitative methods or descriptive quantitative techniques to explore these factors. Qualitative methods lack the attribute of generalizability [15], while most descriptive statistical techniques also fail to unpack the complexity associated with pro-environmental behaviour and its potential determinants. Additionally, there is a limited body of literature exploring the topic in the developing country context, although evidence suggests that these regions record the highest rates of water resource pollution [16]. This limits our understanding of the determinants of pro-environmental behaviour and thus our ability to develop and implement effective policies to encourage the uptake of pro-environmental behaviour $[6,17]$.

Following this, the goal of this study is to establish the factors that affect people's behaviour towards water resources pollution. To do this, we apply the Theory of Planned Behaviour, using structural equation modelling (SEM) to analyse survey data from rural Ghana. Specifically, this study seeks to: (1) explore whether attitudes, subjective norms and perceived behavioural control (PBC) affect intentions to act pro-environmentally in relation to water resources management. (2) Explore whether and how intentions result in pro-environmental behaviours. We contribute to the literature in a number of ways: first, unlike many previous studies in the land and water resources management field that focused on the individual contributions of different factors (such as attitudes, subjective norms and $\mathrm{PBC}$ ), we cover the joint contribution as well as the mechanisms through which these different variables interact. Moreover, the evidence here stems from a rural area in a developing country context, a region that has very limited studies applying second generation statistical techniques to explore the topic. Our contribution is thus expected to advance understanding of the determinants of pro-environmental behaviour and support a step-change in the design and implementation of policies aimed at triggering behavioural changes and enhance water resources management.

The remainder of the paper is structured as follows: in the next section, an overview of the Theory of Planned Behaviour is presented. Next, we present the materials and methodology applied in the research. This is followed by the results section and a discussion of the results. The final section provides the concluding remarks.

\section{Conceptual Overview: The Theory of Planned Behaviour}

The Theory of Reasoned Action (TRA) has been one of the earlier models aimed at providing insights into the relationship between attitudes, subjective norms, intentions and behaviour. Intentions are presumed to be the driving forces determining whether or not a person performs a behaviour; thus, this involves indicators of how much and how hard one is willing to exert, in order to perform a behaviour. Intentions are viewed as direct antecedents of behaviour, with a proposition that, the stronger the intention, the more likely the behaviour will be performed. Further, it is argued that intentions to perform or not to perform a specific behaviour hinges on two key determinants namely; (i) attitude towards the behaviour (refers to the way people feel towards a particular behaviour) and (ii) subjective norms, or the perceived social pressure to perform or not to perform [18]. This theory has however been criticized on the ground that behavioural intentions may not always translate into behaviour due to volitional control [18] and situational factors (e.g., financial ability, time, and available resources) [19]. Additionally, the theory fails to provide clear insights on the affective facets of behaviour [17].

The Theory of Planned Behaviour (TPB) (Figure 1) was propounded by $[18,20]$ to help deal with the limitation inherent in the TRA model. The extension of the TRA has been the inclusion of PBC. PBC was introduced to help account for some influences of situational or non-motivational factors to the performance of a behaviour. This was done on the basiss that non-motivational factors (e.g., time, money, skills, cooperation of others; see Ajzen and Fishbein, 1980, for a discussion) may constrain or facilitate both intentions to perform an action as well as the actual performance of the behaviour in question [18,20]. As a result, it is anticipated that an individual's decision to perform or not to perform an action may depend (to some extent) on whether they feel confident to do it or not, as well as how well they could perform the action (i.e., this epitomises an individual's control over his/her behaviour). 
In sum, the TPB opines that behaviour depends on a combination of intention, attitudes, subjective norms and behavioural control beliefs, in a mediated manner (Figure 1).

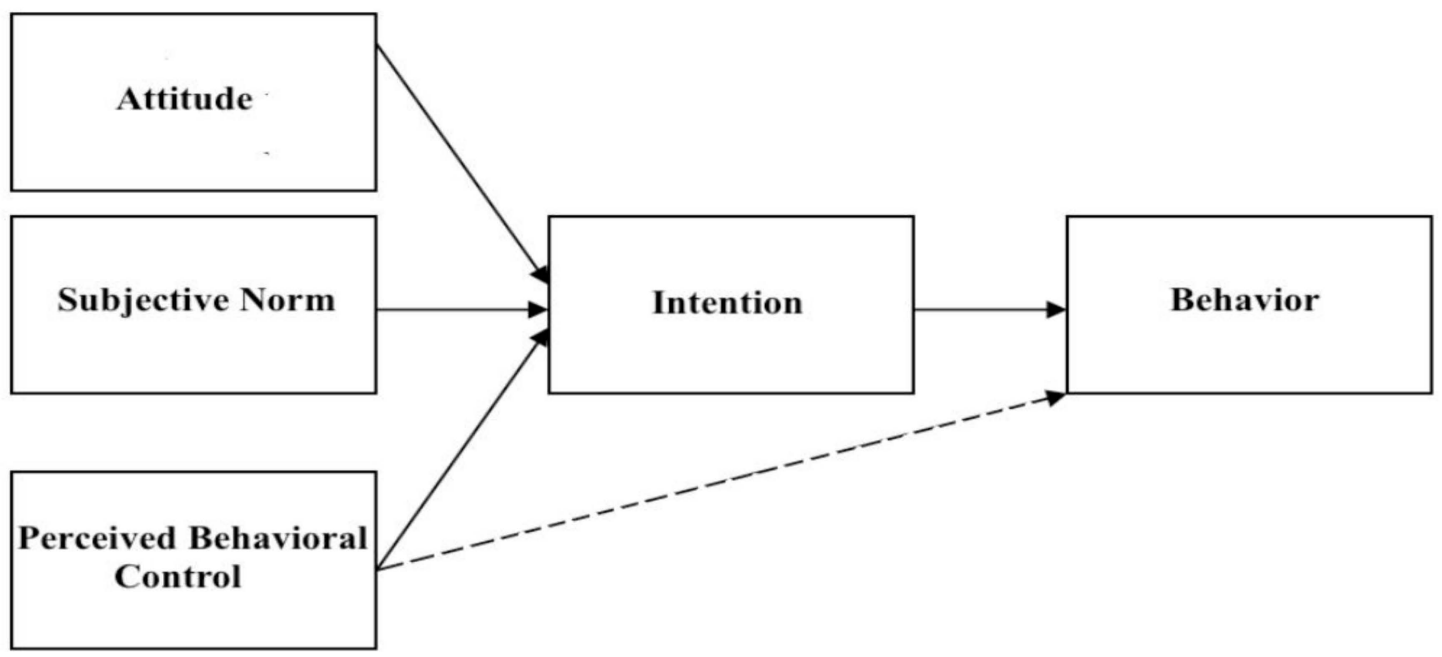

Figure 1. Theory of Planned Behaviour.

Even though the TPB has existed for over three decades, it is still applicable in modern-day studies and has been used in examining specific kinds of environmental behaviours (e.g., recycling, green behaviour, sustainable land management, etc.). Empirical research, for instance, [21] found that among the urban communities, a favourable attitude towards the environment had a corresponding favourable reaction to sanitation, however, this depended on the income status of the people and their ability to access sanitary facilities, highlighting the role of attitudes and PBC, linked to situational factors (e.g., income and cost). Daxini et al. added that subjective norms significantly influenced farmers' intentions to engage in some best land management practices under mandatory conditions [12]. Beyond these empirical studies, some meta-analytic reviews, e.g., [21] have concluded that attitudes, subjective norms, $\mathrm{PBC}$ and intentions are influential factors explaining pro-environmental behaviour.

While many studies provide evidence to support the postulations of the TPB, some studies offer findings that depart from some postulations of the TPB. For instance, while [22] found PBC to have a direct effect on intentions to adopt sustainable transport modes in Ghana, this researcher's evidence does not support the attitude-intention link. These contradictions in the existing pro-environmental literature may be due, in part, to the following reasons: a lack of explicit consideration of the role of situational factors, and methodological and interpretational discrepancies [19]. As the evidence suggests, the TPB has not been applied widely in the developing country context to understand the determinants of pro-environmental behaviours. Given that differences in socio-cultural, ecological and economic factors impact behaviours, we would argue that the predictive capacity of the TPB may vary across different climatic and economic areas. This would further imply that extrapolating the results of studies across regions could be dangerous for policy design due to uncertainties. We believe, therefore, that the application of TPB within the Ghanaian context is a useful contribution to the literature on both pro-environmental behavioural theories and the psychosocial aspects of water resources management.

\section{Materials and Methods}

\subsection{Study Area}

The research was conducted in three rural communities namely, Droboso, Tainso and Asubingya under the Wenchi Municipality in the Brong-Ahafo region of Ghana. The Wenchi Municipality is bounded to the south by Sunyani Municipality and to the north by Kintampo South District (Figure 2). It also shares a common boundary with the Tain District to the west and Techiman Municipality to the 
east. It lies within latitudes $7^{\circ} 30^{\prime} \mathrm{S}$ and $7^{\circ} 15^{\prime} \mathrm{N}$ and longitudes $2^{\circ} 17^{\prime} \mathrm{W}$ and $1^{\circ} 55^{\prime} \mathrm{E}$. In terms of land size, the Municipality covers 1296.6 square kilometres.

The Municipality is well drained with major rivers such as the Tain, Subin, Kyiridi, Trome and Yoyo. The majority of rural dwellers in the municipality rely heavily on these water resources for domestic and industrial activities and livelihood sources [23]. This has resulted in a strong interaction between humans and these water resources, with both positive and negative outcomes. A recent development plan of the Municipal Planning Unit suggests that water-related diseases were among the ten commonest diseases reported in the Municipality [23]. Furthermore, recent reports mention the deteriorating nature of the water resources in these areas [23]. The availability of water resources, the overdependence of the rural populace on such resources and the associated impact of human-environment interactions makes it imperative to investigate factors that determine behaviours towards these water resources. This further justifies the selection of the Wenchi Municipality and the three rural communities as a case study for this research.

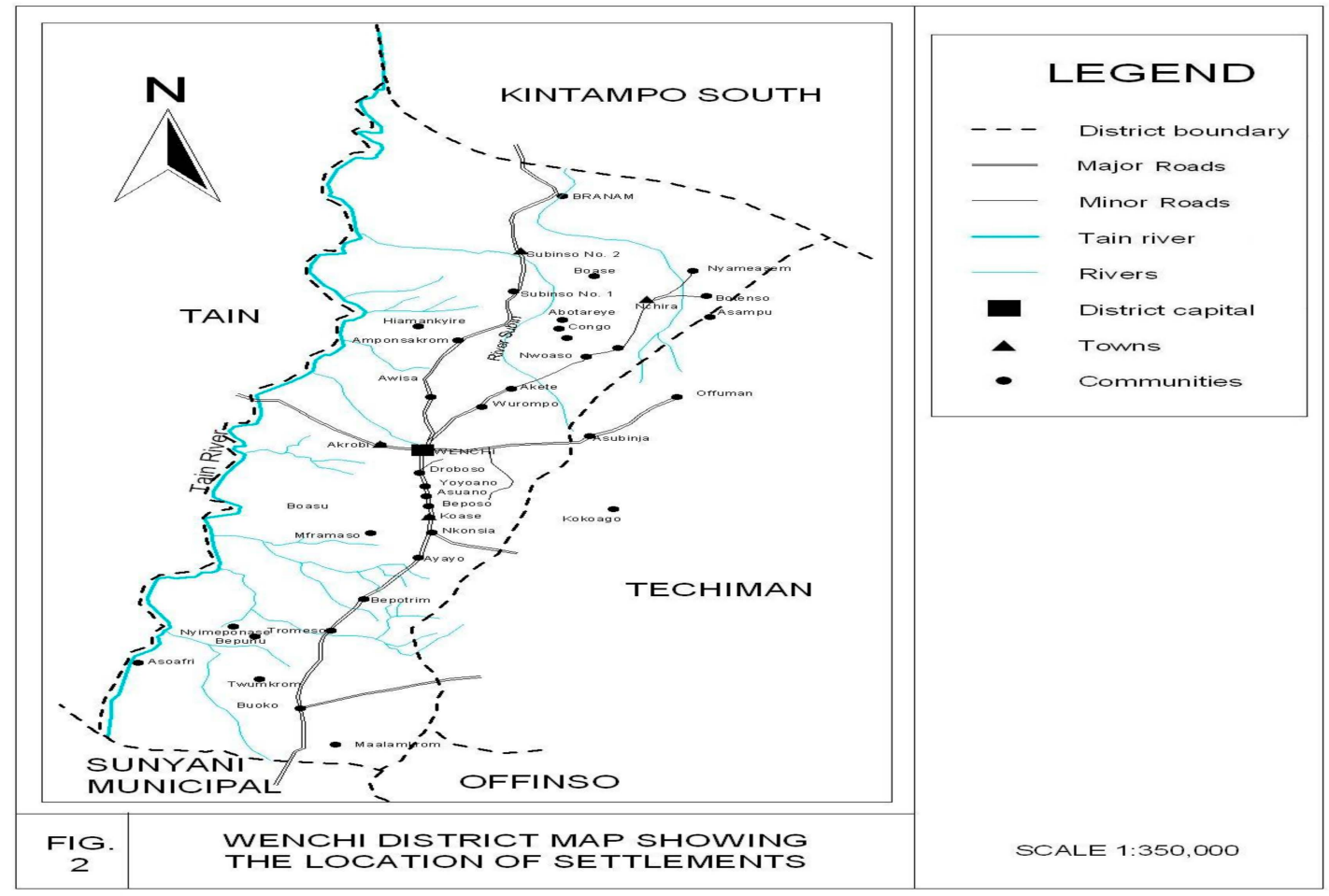

Figure 2. Map of the Wenchi Municipality.

\subsection{Measurement Instrument}

To operationalise the Theory of Planned Behaviour (Figure 1), a Likert type questionnaire was developed and applied in a survey. The questionnaire covered all constructs: attitude, subjective norm, PBC, intention and behaviour. Earlier versions of the questionnaire were reviewed by senior academics who provided feedback on the wording, structure and brevity of statements and the entire instrument. See Table A1 for the final questionnaire applied in the survey. The responses of all statements were captured on a five-point scale (1 to 5), with 1 indicating, for instance, poor environmental attitude and 5 suggesting a strong attitude towards water resources management. For instance, selecting "very likely" to a statement such as "I intend to stop dropping litter around the riverbank or into the river" shows an extremely positive intention to act pro-environmentally, hence, this scores 5 while others (quite likely, neutral, somewhat unlikely and very unlikely) score 4, 3, 2 and 1, respectively. On the other hand, responses to negatively worded statements (e.g., "Bathing around the riverbank or in the river (using chemicals)") were reverse coded: the numerical scoring scale runs in the antithetical direction. This is because the act opposes the goal of water sources management, therefore, if an individual 
indicates that doing that is "totally enjoyable", then they score the lowest (1), while others (enjoyable, neutral, unenjoyable and totally unenjoyable) score 2, 3, 4 and 5, respectively.

The questionnaire covered two other components: the first part focused on socio-demographic characteristics of survey participants such as age, gender, educational attainment, employment status and occupation while the last section aimed at eliciting further qualitative data. These socio-demographic variables were included in the questionnaire as evidence which suggests that these variables have an influence on environmental attitudes and behaviours, e.g., [19,24]. Therefore, including such variables in our model as moderators-factors that contingently influence the statistical significance, direction and/or strength of the relationship between two or more other variables-will advance our understanding of the role of attitudes, subjective norms, PBC and intentions in explaining pro-environmental behaviour [25].

\subsection{Data Collection and Profile of Participants}

A face-to-face survey was implemented in the three rural communities between December 2018 and February 2019. A total of 510 responses were obtained from participants. Next, we examined the data to help detect missing data. We observed that there were no cases with more than $5 \%$ missing data. Following this, all 510 cases were retained as the total number of usable responses. Table 1 provides a summary of participants' socio-economic characteristics. The survey was dominated by males, people without a university degree, Christians and participants were relatively young, with a median age of 32 (we report the median because the data was not normally distributed: (Kolmogorov-Smirnov statistic $=0.109$; degree of freedom $=510 ; p$-value $<0.001)$, thus making the mean an unreliable statistic in this case).

Table 1. Socio-economic characteristic of respondents.

\begin{tabular}{ccc}
\hline Variable & Group & Percentage \\
\hline \multirow{2}{*}{ Gender } & Male & 60.6 \\
\cline { 2 - 3 } & Female & 39.4 \\
\hline \multirow{2}{*}{ Educational attainment } & No qualification & 17.5 \\
\cline { 2 - 3 } & High school & 42.4 \\
\cline { 2 - 3 } & Diploma, short course certificate & 20.8 \\
\hline \multirow{2}{*}{ Religion } & With a university degree & 19.4 \\
\cline { 2 - 3 } & Christian & 89.4 \\
\cline { 2 - 3 } & Muslim & 10.2 \\
\cline { 2 - 3 } & Others & 0.4 \\
\hline
\end{tabular}

Age: median $=32 ;$ mean $=33.5 ;$ mode $=27 ;$ standard deviation $=10.4$

Notes: $n=510$; the category "others" under religion refers to Buddhist, Hindu, Afrikaans and Atheist.

\subsection{Analytical Methods}

The statements under each construct were used to obtain the latent variables. Each construct contained more than one statement and all statements for each construct are assumed to be unidimensional [26]. Following this, we used Cronbach's alpha to examine internal consistency among the different scale items. An alpha of at least 0.70 is deemed reliable and widely recommended $[27,28]$.

The Theory of Planned Behaviour is essentially a mediation model. Thus, to test it, we applied SEM. SEM is appropriate for the present study as it allows for the exploration of the complex mechanisms through which individual constructs transmit their effect onto others [25] and has been applied extensively to understand human attitudes, intrinsic values, motivations and behaviours, e.g., [12-14,29]. Additionally, the technique enables an appraisal of the validity and reliability of observed model parameter estimates $[25,30]$. The use of SEM has an advantage over first-generation 
statistical procedures—such as multiple regression—as the technique enables the researcher to consider types of error confounding [31].

The SEM was ran using a combination of Statistical Package for Social Sciences (SPSS) IBM version 24 and the lavaan package within RStudio (0.5-23.1097) [32]. In the TPB model, behaviour is classified as the dependent variable, while attitude, $\mathrm{PBC}$ and subjective norm are classified as the independent variables, with intention acting as a mediator. As hypothesised in the TPB, PBC may directly influence behaviour, therefore, we regressed $\mathrm{PBC}$ directly on behaviour (Figure 2). Each of these (latent) variables were derived from directly observed indicators (see Section 3.2). The process was implemented in two stages: first, confirmatory factor analysis to measure the latent variables using the multiple observed indicators, and second, a path analysis to test hypothesised causal structures between two or more variables (i.e., the structural paths in the model). The diagonally weighted least squares (DWLS) was applied as the model estimation method, as this method appears to work well under many situations such as dealing with small sample sizes, and categorical and ordinal data with non-normal distributions [33].

\section{Results}

\subsection{Overview of Survey Responses}

In this section, we present an overview of the descriptive statistics obtained for all constructs. Results in Table 2 show that a high (summated) mean score was recorded for all constructs. Similar results were obtained for individual statements across all constructs with the exception of "attitude" where one statement recorded a relatively low (mean $=2.46$ ) mean score. This low mean score was recorded for a statement (attitude 2) which suggests that respondents enjoy bathing around the riverbank or in the river (using chemical), an attitude that is contrary to the goals of water resources management. With the exception of attitude which falls well below the recommended threshold of 0.7, Cronbach's alpha for other variables do not depart much from the recommended threshold. Ajzen notes that:

"For theoretical reasons, this requirement is not imposed on the belief-based measures of attitude because no assumption is made that accessible beliefs are internally consistent. People's attitudes toward a behaviour can be ambivalent if they believe that the behaviour is likely to produce positive as well as negative outcomes. Consequently, internal consistency is not a necessary feature of belief-based measures of attitude. It is in their aggregate that they provide a single manifest indicator of the latent construct";

(Ajzen, 2002, p. 8)

In this study, we found such a contradiction for people who enjoyed bathing around the river bank or in the river).

\subsection{What Factors Influence Behaviour Towards Water Resources Management?}

To assess whether and how the variables of the TPB (Figure 1) affect behaviour towards water resources management, a mediation was tested. The fit of the proposed model was evaluated by means of the Chi-squared $\left(\chi^{2}\right)$ test significance, the comparative fit index $(\mathrm{CFI})$, the root mean square error of approximation (RMSEA), the standard root mean square residual (SRMR) and the Tucker-Lewis index (TLI) as is widely recommended in the literature (Hu and Bentler, 1999; Hooper et al., 2008; Garson, 2015). Results show a satisfactory fit with the data: $\chi^{2}(n=510$, degrees of freedom $(\mathrm{df})=225)$ $=0.000, p<0.000 ; \mathrm{CFI}=0.907 ; \mathrm{TLI}=0.962 ; \mathrm{RMSEA}=0.035$; and SRMR $=0.063$ (see Table A2, see also, Hooper et al., 2008 for recommended cut-offs for these indexes).

Results in Table 3 show that the paths linking attitude and intention $(p<0.01), \mathrm{PBC}$ and intention $(p<0.001)$ and intention and behaviour $(p<0.001)$ are significant, indicating that environmental attitudes and $\mathrm{PBC}$ influence individuals' intentions to act and this in turn, translates into pro-environmental behaviour 
(see also Figure 3). Consequently, the results suggest that the effects of attitudes and PBC are mediated by intentions. The results further indicate that attitude and PBC, together, explained $64.3 \%$ of the variation in intentions, while intentions explained $37.8 \%$ of the variation in behaviour, suggesting that these variables have a high explanatory power in intentions and behaviours. However, we did not find evidence to support the subjective norm-intention, and the PBC-behaviour links $(p>0.05)$. It is also worth noting that all observed variables yielded a positive link with the latent variables with the exception of the second statement on attitude, where the majority of respondents indicated that they enjoyed bathing around the riverbank or in the river (using chemical). It is therefore not surprising to find a negative link between this statement and the latent variable as this attitude opposes the goals of water resources management.

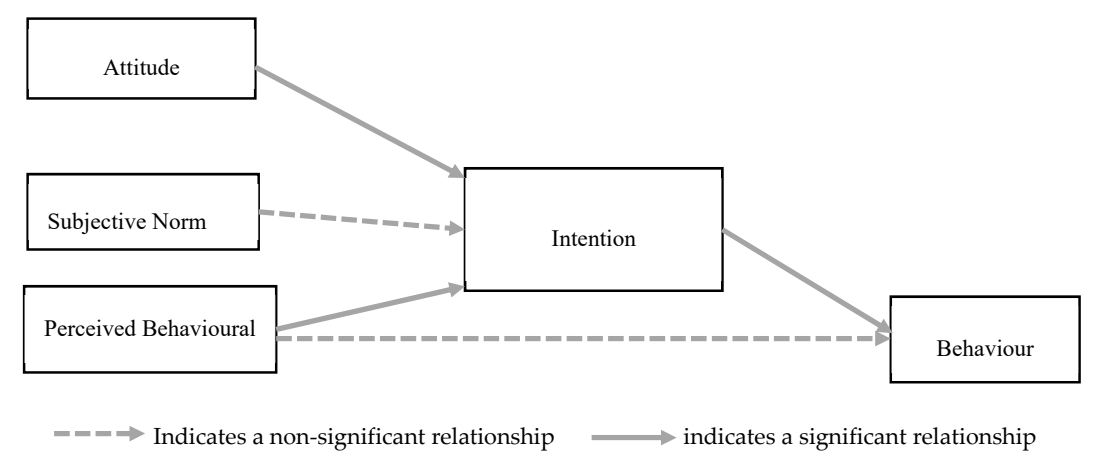

Figure 3. Final model after testing the Theory of Planned Behaviour. Note: All significant paths are positive relationships. 
Table 2. Descriptive results of respondents' evaluation of survey items.

\begin{tabular}{|c|c|c|c|c|}
\hline Construct & Items & Mean & Standard Deviation & Cronbach's Alpha \\
\hline \multirow{5}{*}{ Attitude } & - & 4.19 & - & 0.46 \\
\hline & $\begin{array}{l}\text { Attitude } \_1=\text { Washing bicycle, tricycle, car, lorry or clothes (using chemical soap) around the } \\
\text { riverbank or in the river is }\end{array}$ & 4.70 & 0.570 & \\
\hline & Attitude $\_2=$ Bathing around the riverbank or in the river (using chemical) is & 2.46 & 1.193 & \\
\hline & Attitude _3 = For me to defecate around the riverbank or in the river would be & 4.90 & 0.295 & \\
\hline & Attitude $\_4=$ For me to drop litter around the riverbank or into the river would be & 4.70 & 0.619 & \\
\hline \multirow{7}{*}{$\begin{array}{l}\text { Subjective } \\
\text { norm }\end{array}$} & - & 4.61 & - & 0.63 \\
\hline & $\begin{array}{l}\text { Subjective norm_1 }=\text { The people in my life whose opinions I value drop litter around the } \\
\text { riverbank or into the river }\end{array}$ & 4.67 & 0.693 & \\
\hline & $\begin{array}{l}\text { Subjective norm } \_2=\text { Most people who are important to me defecate around the riverbank } \\
\text { or in the river }\end{array}$ & 4.72 & 0.723 & \\
\hline & $\begin{array}{l}\text { Subjective norm } 3=\text { It is expected of me that I wash my bicycle, tricycle, car, lorry or clothes } \\
\text { around the riverbank or in the river }\end{array}$ & 4.38 & 0.969 & \\
\hline & $\begin{array}{l}\text { Subjective norm } \_4=\text { The people in my life whose opinions I value would approve of me } \\
\text { dropping litter around the riverbank or into the river }\end{array}$ & 4.68 & 0.590 & \\
\hline & $\begin{array}{l}\text { Subjective norm } \_5=\text { The people in my life whose opinions I value wash their bicycle, } \\
\text { tricycle, car, lorry or clothes around the riverbank }\end{array}$ & 4.63 & 0.812 & \\
\hline & $\begin{array}{l}\text { Subjective norm } \_6=\text { Most people who are important to me think that bathing around the } \\
\text { riverbank or in the river is good }\end{array}$ & 4.57 & 0.743 & \\
\hline
\end{tabular}


Table 2. Cont

\begin{tabular}{|c|c|c|c|c|}
\hline Construct & Items & Mean & Standard Deviation & Cronbach's Alpha \\
\hline \multirow{6}{*}{$\begin{array}{l}\text { Perceived } \\
\text { behavioural } \\
\text { control }\end{array}$} & - & 4.33 & - & 0.53 \\
\hline & PBC_1 = Whether I defecate around the riverbank or in the river depends very much on me & 4.13 & 1.243 & \\
\hline & PBC_2 = For me to stop dropping litter around the riverbank or into the river will be & 4.68 & 0.638 & \\
\hline & PBC_3 = I don't have control over whether I defecate around the riverbank or in the river & 4.28 & 0.980 & \\
\hline & $\begin{array}{l}\mathrm{PBC}_{-} 4=\mathrm{I} \text { am unsure I can stop washing my bicycle, tricycle, car, lorry or clothes around the } \\
\text { riverbank or in the river }\end{array}$ & 3.99 & 0.997 & \\
\hline & PBC_5 = For me to stop dropping litter around the riverbank or into the river will be & 4.54 & 0.972 & \\
\hline \multirow{5}{*}{ Intention } & - & 4.81 & - & 0.60 \\
\hline & Intention_1 = I intend to stop dropping litter around the riverbank or into the river & 4.74 & 0.589 & \\
\hline & $\begin{array}{l}\text { Intention_ } 2=\text { I will not defecate around the riverbank or into the river (even if I have done it } \\
\text { in the past) }\end{array}$ & 4.91 & 0.408 & \\
\hline & $\begin{array}{l}\text { Intention_3 = I will try not wash my bicycle, tricycle, car, lorry or clothes around the } \\
\text { riverbank or in the river }\end{array}$ & 4.79 & 0.600 & \\
\hline & Intention_4 = I will not bath around the riverbank or in the river (using chemical soap) & 4.79 & 0.556 & \\
\hline \multirow{5}{*}{ Behaviour } & - & 4.90 & - & 0.59 \\
\hline & Behaviour $\_\mathbf{1}=$ Defecating around the riverbank or in the river in the past 12 months & 4.98 & 0.145 & \\
\hline & $\begin{array}{l}\text { Behaviour } \_2=\text { Dropping litter (e.g., cigarette, condoms, cotton swabs, diapers, paper towels } \\
\text { and wipes) around the riverbank or into the river in the past } 12 \text { months }\end{array}$ & 4.92 & 0.294 & \\
\hline & $\begin{array}{l}\text { Behaviour } 3=\text { Washing bicycle, tricycle, car, lorry or clothes (using chemical soap) around } \\
\text { the riverbank or in the river in the past } 12 \text { months }\end{array}$ & 4.82 & 0.612 & \\
\hline & $\begin{array}{l}\text { Behaviour } \_4=\text { Bathing around the riverbank or in the river (using chemical soap) in the past } \\
12 \text { months }\end{array}$ & 4.89 & 0.468 & \\
\hline
\end{tabular}


Table 3. Results of regression paths for the structural model.

\begin{tabular}{|c|c|c|c|c|c|}
\hline Observed Variables & Latent Variables & Estimate & Std. Err & $p$-Value & Squared Multiple Correlation \\
\hline Attitude_1 & Attitude & 0.522 & 0.075 & $0.000^{* * *}$ & 0.840 \\
\hline Attitude _2 & Attitude & -0.169 & 0.061 & $0.005^{* *}$ & 0.020 \\
\hline Attitude_3 & Attitude & 0.032 & 0.015 & $0.030 *$ & 0.012 \\
\hline Attitude _4 & Attitude & 0.148 & 0.034 & $0.000 * * *$ & 0.057 \\
\hline Subjective norm_1 & Subjective norm & 0.236 & 0.036 & $0.000 * * *$ & 0.116 \\
\hline Subjective norm _2 & Subjective norm & 0.309 & 0.037 & $0.000^{* * *}$ & 0.183 \\
\hline Subjective norm _3 & Subjective norm & 0.649 & 0.050 & $0.000^{* * *}$ & 0.449 \\
\hline Subjective norm_4 & Subjective norm & 0.081 & 0.031 & $0.010 *$ & 0.019 \\
\hline Subjective norm _5 & Subjective norm & 0.456 & 0.042 & $0.000^{* * *}$ & 0.316 \\
\hline Subjective norm_6 & Subjective norm & 0.426 & 0.038 & $0.000^{* * *}$ & 0.329 \\
\hline PBC_1 & PBC & 0.146 & 0.069 & $0.035^{*}$ & 0.014 \\
\hline PBC_2 & PBC & 0.232 & 0.035 & $0.000^{* * *}$ & 0.133 \\
\hline PBC_3 & PBC & 0.531 & 0.053 & $0.000^{* * *}$ & 0.295 \\
\hline PBC_4 & PBC & 0.547 & 0.054 & $0.000^{* * *}$ & 0.302 \\
\hline PBC_5 & PBC & 0.464 & 0.053 & $0.000^{* * *}$ & 0.228 \\
\hline Intention_1 & Intention & 0.146 & 0.028 & $0.000^{* * *}$ & 0.176 \\
\hline Intention_2 & Intention & 0.092 & 0.018 & $0.000^{* * *}$ & 0.146 \\
\hline Intention_3 & Intention & 0.158 & 0.029 & $0.000^{* * *}$ & 0.200 \\
\hline Intention_4 & Intention & 0.202 & 0.034 & $0.000^{* * *}$ & 0.387 \\
\hline Behaviour_1 & Behaviour & 0.004 & 0.005 & 0.386 & 0.001 \\
\hline Behaviour_2 & Behaviour & 0.103 & 0.010 & $0.000 * * *$ & 0.199 \\
\hline
\end{tabular}


Table 3. Cont.

\begin{tabular}{cccccc}
\hline Observed Variables & Latent Variables & Estimate & Std. Err & $p$-Value & Squared Multiple Correlation \\
\hline Behaviour_3 & Behaviour & 0.180 & 0.021 & $0.000^{* * *}$ & 0.140 \\
\hline Behaviour_4 & Behaviour & 0.370 & 0.034 & $0.000^{* * *}$ & 0.210 \\
\hline Independent Variable & Dependent Variable & Estimate & Std. Err & $p$-Value & Squared Multiple Correlation \\
\hline Attitude & Intention & 0.903 & 0.260 & $0.001^{* *}$ & 0.643 \\
\hline PBC & Intention & 0.992 & 0.221 & $0.000^{* * *}$ & - \\
\hline Subjective norm & Intention & -0.074 & 0.095 & 0.435 & - \\
\hline PBC & Behaviour & 0.047 & 0.091 & 0.605 & $0.000^{* * *}$ \\
\hline Intention & Behaviour & 0.449 & 0.093 & 0.378 \\
\hline
\end{tabular}

Notes: refer to Table 2 for meaning of the respective observed variables (e.g., Attitude_1, Attitude_2); PBC $=$ perceived behavioural Control; ${ }^{* * *} p$-value $<0.001,{ }^{* *} p$-value $<0.01,{ }^{*} p$-value $<0.05$. 


\section{Discussion and Concluding Remarks}

This study aimed at applying the Theory of Planned Behaviour to explore whether and how environmental attitudes, subjective norms, $\mathrm{PBC}$ and intentions affect pro-environmental behaviour regarding water resources management. There are a few limitations which we clarify before moving on to discuss our results. For instance, although self-reported measures of environmental attitudes and behaviours have been well established in the environmental management scholarship, they are not without limitations. Evidence suggests that survey respondents tend to overreport positive attitudes and behaviours due to social desirability bias [34] and limited memory. Therefore, we encourage future studies to apply objective measures of assessment.

Applying objective or observed measures of evaluation could impact the study's outcomes and help improve accuracy. For instance, if the research monitored how survey participants behaved by observing them and gathering data on their practices, this could reduce the tendency of participants reporting "positive" behaviours in order to project a favourable image of themselves (when such reports are not a true reflection of their actions). Moreover, observed measures would help provide more accurate reports of the frequency and consistency with which survey participants acted pro-environmentally anytime they visited the water resources. This is because the records of observed behaviours are more reliable than survey participants' evaluation of such behaviours. Thus, observed measures are likely to reflect a different reality, which self-reports fail to reveal due to participants' desire to report the ideal conservation behaviour [35-37].

Results show that attitude and PBC have a strong explanatory power in people's intentions (explained $64.3 \%$ of the variation in intentions) and intentions are influential in determining pro-environmental behaviour (explained $37.8 \%$ of the variation in behaviour). The result that attitudes influence intentions (as hypothesized in the Theory of Planned Behaviour) confirms the finding of previous studies, e.g., [12,21]. Indeed, when people disfavour an act, they are unlikely to demonstrate their readiness to engage in that act. For instance, in this study, a majority of survey participants indicated their dislike for unsustainable environmental practices such as dropping litter, and defecating around the riverbank or in the river, among others. Such negative feelings regarding the practice discourage an individual from engaging in such acts, and thus, their readiness not to do that [18-20]. Attitudes are therefore a key determinant of behavioural intentions.

Results further revealed that PBC affects intentions to act pro-environmentally. This suggests that strong intenders have stronger faith in their ability to engage in the recommended pro-environmental behaviours. It was also revealed that intentions had a positive influence on pro-environmental behaviour, thus, strong intenders were more likely to have engaged in the recommended pro-environmental behaviours. However, we do not find evidence to support the subjective norm-intention and the PBC-behaviour links. The lack of evidence for these links may be attributed to the omission of situational factors that can potentially mediate and/or moderate the subjective norm-intention and the PBC-behaviour links. This finding, perhaps, highlights a key limitation of the TPB in accounting for the role of situational factors in predicting behaviours, particularly where the interest lies in discriminating between the frequency and consistency of a behaviour as opposed to simply looking at performance versus non-performance [38]. This is because situational factors could either facilitate of constrain these links. For instance, although an individual may perceive themselves to have the capacity to engage in a particular action, situational factors (e.g., the lack of facilities) may act as a barrier $[6,19]$. As one respondent noted in this study, some people engage in open defecation around the riverbank because of a lack of toilet facilities near the river. This is a situation that is common among many rural and peri-urban areas in Ghana, see [24]. In emergency situations, PBC may not be a good predictor of behaviour. Actual behavioural control therefore may perform better and needs to be considered where situational factors are not explicitly modelled as mediators and/or moderators.

Additionally, the lack of evidence to support the subjective norm-intention link may be due to cultural and affective factors which the TPB does not explicitly account for, e.g., [17]. Responses to the questions evaluating subjective norms show a lack of variation in answers as almost all respondents 
indicated that their families and friends (including other people whose opinions mattered to them) would not approve of the performance of the 'negative' practices stated in the survey (e.g., open defecation). As explained by [19], cultural traditions or beliefs may influence people's perceptions, which in turn affect intentions. For instance, if the dominant culture encourages practices that are unsustainable (e.g., bathing in the river), people will be less conscious of the consequences of performing such behaviours and are more likely to engage in them [19]. To advance our understanding of the drivers of pro-environmental behaviour, it would be good to design a cross-cultural study that looks at the predictive power of the TPB model.

An institutionalist approach may be useful in advancing our understanding of the determinants of pro-environmental behaviour. For instance, exploring the multiplicity of factors that interact to determine behaviours will be important; however, we were unable to test for potential moderators such as age, employment status, gender and educational status due to limited sample size for the proposed model. Indeed, past empirical studies have shown that the drivers of pro-environmental behaviour may differ across various social classes, genders, etc. These studies have shown that women are more likely to be environmentally conscious due to their gender socialization [39] and value systems [40]. In rural Ghana, just like many sub-Saharan African countries, women engage more in household activities that are directly linked to water management [41,42] and are therefore more likely to be conscious of the links between water wastage, pollution and management. Furthermore, whether people are able to support water protection policies (e.g., a ban on unsafe measures of mining) or not may depend on their employment status, as individuals who are economically well positioned may have less economic problems to worry about, all things being equal [43]. Therefore, people in different groups may have different 'realities' based on the socio-cultural and economic circumstances, and these drive behaviours. It is therefore important that these hypotheses are tested to unpack the complex interaction among TPB variables, socio-economic variables and cultural variables using multivariate quantitative techniques (e.g., the conditional process analysis) [25]. Qualitative approaches could be employed to gather deep and rich data to complement such multivariate quantitative analysis. This improved understanding may help to design well-targeted policies that respond to the motivations, capacities and circumstances of diverse groups [44].

From a policy perspective, our findings suggest that policymakers and regulators need to consider the role of TPB variables when attempting to encourage behaviours aimed at reducing water pollution. Moreover, findings suggest that policymakers need to pay attention to situational factors. Evidence suggests that people are less likely to behave pro-environmentally when the necessary conditions are not met $[6,44]$. Blake notes that, where people feel it is the government's responsibility to provide the conditions necessary for engaging in pro-environmental behaviours, they are less likely to ascribe to themselves the responsibility to act pro-environmentally if the conditions are not met [45]. In line with this assertion, this study has revealed that the limited availability of water and sanitation facilities (such as toilet facilities) that characterise many rural and peri-urban communities in Ghana [24] contributes to poor environmental practices (e.g., open defecation in rivers and/or around the riverbank). Therefore, where such facilities are lacking, it is important that they are provided by the government and community authorities.

We note, however, that the provision of water and sanitation facilities may not guarantee the performance of pro-environmental behaviours. This is because past behaviours or habits may hinder the performance of environmentally responsible behaviours [19]. As found in this study, more than half of survey participants reported that they enjoy bathing in and/or around the river. If this feeling has persisted for a relatively long time, it might be difficult to change it. Policymakers and regulators therefore need to consistently encourage the uptake of such behaviours through, for example, highlighting the consequences of such actions and formulating laws to regulate those practices. Further efforts may be required to understand how best to frame such messages - negative or positive- and whether different framings are best suited to different socio-economic groups. This is because the success of informative strategies depends on the source of the information, and how messages are framed and delivered $[6,11,44]$. 
The cultural factor suggests that policies aimed at safeguarding water resources need to consider local values and belief systems. This study has revealed that normative beliefs may be crucial as people feel obliged to perform certain actions due to cultural concerns. Policymakers and regulators could therefore use this as an opportunity to carefully integrate existing socio-cultural beliefs into formal regulatory measures to help protect water resources [46]. As Ayer noted, where there are long-standing norms or conventions on local resource use, communication and transaction costs are substantially lower than the cost involved in complete external intervention [47]. Moreover, where external regulations are incompatible with local practices and belief systems (due to lack of knowledge regarding the socio-ecological and cultural context), regulations may be fiercely rejected by local resource users [48,49]. Integrating local beliefs with scientific knowledge and regulatory measures is thus an efficient way to encourage pro-environmental behaviours in the local context [49-51]. This could help increase the uptake of behaviours aimed at reducing water pollution, and ultimately contribute to improved water quality.

Author Contributions: Conceptualization, M.O. and A.S.Y.; methodology, M.O., and A.S.Y.; software, M.O.; formal analysis, M.O., A.S.Y., and E.N.; investigation, M.O., A.S.Y., and R.A.A.; resources, E.N.; data curation, A.S.Y.; writing—original draft preparation, M.O., A.S.Y., E.N., and R.A.A.; writing-review and editing, M.O., and A.S.Y.

Funding: This research received no external funding.

Acknowledgments: The authors are grateful to Richard Afriyie Oduro (University of Leeds) and two anonymous reviewers for their insightful comments on an earlier version of the paper.

Conflicts of Interest: The authors declare no conflict of interest. 


\section{Appendix A}

Table A1. Questionnaire.

\begin{tabular}{|c|c|c|c|c|c|c|c|}
\hline \multicolumn{8}{|c|}{ Socio-Demographic Characteristics } \\
\hline 1 & Gender & \multicolumn{6}{|l|}{ Male [1], Female [2], Prefer not to say [3] } \\
\hline 2 & Education & \multicolumn{6}{|c|}{$\begin{array}{l}\text { Select your highest level of educational attainment. This should be the highest qualification obtained. No qualification [1], JHS/JSS or SHS/SSS [2], Diploma, short course } \\
\text { certificates [3], University degree (e.g., BSc. BA., LLB. BCOM, MSC. MA. MPhil. PhD) [4] }\end{array}$} \\
\hline 3 & Age (in years) & & & & & & \\
\hline 4 & Employment & \multicolumn{6}{|l|}{ Unemployed [1], Student [2], Farmer [3], Fisher folk [4], Others (e.g., fish monger) [5] } \\
\hline 5 & Religion & \multicolumn{6}{|l|}{ Christian [1], Muslim [2], Traditionalist [3], Others (e.g., Atheist, Buddhist, etc.) [4] } \\
\hline \multirow{4}{*}{ Behaviour } & & $\begin{array}{l}\text { Dropping litter (e.g., cigarettes, condoms, cotton swabs, diapers, medication/drugs, needles, } \\
\text { paper towels and/or wipes) around the riverbank or into the river in the past } 12 \text { months }\end{array}$ & Never & Very Rarely & $\begin{array}{l}\text { About Half } \\
\text { the time }\end{array}$ & Very Often & Always \\
\hline & & Defecating around the riverbank or in the river in the past 12 months & Never & Very Rarely & $\begin{array}{l}\text { About Half } \\
\text { the time }\end{array}$ & Very Often & Always \\
\hline & & $\begin{array}{l}\text { Washing bicycle, tricycle, car, lorry or clothes (using chemical soap) around the riverbank or } \\
\text { in the river in the past } 12 \text { months }\end{array}$ & Never & Very Rarely & $\begin{array}{l}\text { About Half } \\
\text { the time }\end{array}$ & Very Often & Always \\
\hline & & Bathing around the riverbank or in the river (using chemical soap) in the past 12 months & Never & Very Rarely & $\begin{array}{l}\text { About Half } \\
\text { the time }\end{array}$ & Very Often & Always \\
\hline \multirow{4}{*}{\multicolumn{2}{|c|}{ Attitudes }} & For me to drop litter around the riverbank or into the river would be & $\begin{array}{l}\text { Totally } \\
\text { Unpleasant }\end{array}$ & $\begin{array}{l}\text { Somewhat } \\
\text { Unpleasant }\end{array}$ & Neutral & $\begin{array}{l}\text { Somewhat } \\
\text { pleasant }\end{array}$ & Pleasant \\
\hline & & For me to defecate around the riverbank or in the river would be & Very bad & Bad & Neutral & Good & Very Good \\
\hline & & Bathing around the riverbank or in the river (using chemical soap) is & $\begin{array}{l}\text { Totally } \\
\text { unenjoyable }\end{array}$ & Unenjoyable & Neutral & Enjoyable & $\begin{array}{l}\text { Totally } \\
\text { Enjoyable }\end{array}$ \\
\hline & & $\begin{array}{l}\text { Washing bicycle, tricycle, car, lorry or clothes (using chemical soap) around the riverbank or } \\
\text { in the river is }\end{array}$ & $\begin{array}{l}\text { Really } \\
\text { Harmful }\end{array}$ & $\begin{array}{l}\text { Somewhat } \\
\text { Harmful }\end{array}$ & Neutral & $\begin{array}{l}\text { Moderately } \\
\text { Beneficial }\end{array}$ & $\begin{array}{l}\text { Really } \\
\text { Beneficial }\end{array}$ \\
\hline \multirow{6}{*}{\multicolumn{2}{|c|}{ Subjective norm }} & $\begin{array}{l}\text { The people in my life whose opinions I value would approve of me dropping litter around } \\
\text { the riverbank or into the river }\end{array}$ & $\begin{array}{l}\text { Completely } \\
\text { disagree }\end{array}$ & $\begin{array}{l}\text { Somewhat } \\
\text { disagree }\end{array}$ & Neutral & $\begin{array}{l}\text { Somewhat } \\
\text { agree }\end{array}$ & $\begin{array}{l}\text { Completely } \\
\text { agree }\end{array}$ \\
\hline & & $\begin{array}{l}\text { It is expected of me that I wash my bicycle, tricycle, car, lorry or clothes around the riverbank } \\
\text { or in the river }\end{array}$ & $\begin{array}{l}\text { Completely } \\
\text { false }\end{array}$ & $\begin{array}{l}\text { Somewhat } \\
\text { false }\end{array}$ & Neutral & $\begin{array}{l}\text { Somewhat } \\
\text { true }\end{array}$ & $\begin{array}{l}\text { Completely } \\
\text { true }\end{array}$ \\
\hline & & $\begin{array}{l}\text { Most people who are important to me think that bathing around the riverbank or in the river } \\
\text { is good }\end{array}$ & $\begin{array}{l}\text { Completely } \\
\text { false }\end{array}$ & $\begin{array}{l}\text { Somewhat } \\
\text { false }\end{array}$ & Neutral & $\begin{array}{l}\text { Somewhat } \\
\text { true }\end{array}$ & $\begin{array}{l}\text { Completely } \\
\text { true }\end{array}$ \\
\hline & & Most people who are important to me defecate around the riverbank or in the river & $\begin{array}{l}\text { Completely } \\
\text { false }\end{array}$ & $\begin{array}{l}\text { Somewhat } \\
\text { false }\end{array}$ & Neutral & $\begin{array}{l}\text { Somewhat } \\
\text { true }\end{array}$ & $\begin{array}{l}\text { Completely } \\
\text { true }\end{array}$ \\
\hline & & $\begin{array}{l}\text { The people in my life whose opinions I value wash their bicycle, tricycle, car, lorry or clothes } \\
\text { around the riverbank or in the river }\end{array}$ & $\begin{array}{l}\text { Completely } \\
\text { false }\end{array}$ & $\begin{array}{l}\text { Somewhat } \\
\text { false }\end{array}$ & Neutral & $\begin{array}{l}\text { Somewhat } \\
\text { true }\end{array}$ & $\begin{array}{l}\text { Completely } \\
\text { true }\end{array}$ \\
\hline & & The people in my life whose opinions I value drop litter around the riverbank or into the river & $\begin{array}{l}\text { Completely } \\
\text { false }\end{array}$ & $\begin{array}{l}\text { Somewhat } \\
\text { false }\end{array}$ & Neutral & $\begin{array}{l}\text { Somewhat } \\
\text { true }\end{array}$ & $\begin{array}{l}\text { Completely } \\
\text { true }\end{array}$ \\
\hline
\end{tabular}


Table A1. Cont.

\begin{tabular}{|c|c|c|c|c|c|c|}
\hline \multicolumn{7}{|c|}{ Socio-Demographic Characteristics } \\
\hline \multirow{5}{*}{$\begin{array}{l}\text { Perceived } \\
\text { behavioural control }\end{array}$} & For me to stop dropping litter around the riverbank or into the river will be & $\begin{array}{l}\text { Totally } \\
\text { impossible }\end{array}$ & Impossible & Neutral & $\begin{array}{l}\text { Moderately } \\
\text { Possible }\end{array}$ & Very possible \\
\hline & Whether I defecate around the riverbank or in the river depends very much on me. & $\begin{array}{l}\text { Completely } \\
\text { false }\end{array}$ & $\begin{array}{l}\text { Somewhat } \\
\text { false }\end{array}$ & Neutral & $\begin{array}{l}\text { Somewhat } \\
\text { true }\end{array}$ & $\begin{array}{l}\text { Completely } \\
\text { true }\end{array}$ \\
\hline & $\begin{array}{l}\text { I am unsure I can stop washing my bicycle, tricycle, car, lorry or clothes around the riverbank } \\
\text { or in the river. }\end{array}$ & Very unsure & $\begin{array}{l}\text { A Little } \\
\text { unsure }\end{array}$ & Neutral & $\begin{array}{l}\text { Moderately } \\
\text { sure }\end{array}$ & Very sure \\
\hline & For me to stop dropping litter around the riverbank or into the river will be & Impossible & Very Difficult & Neutral & $\begin{array}{l}\text { Somewhat } \\
\text { Possible }\end{array}$ & Easy \\
\hline & I don't have control over whether I defecate around the riverbank or in the river & $\begin{array}{l}\text { No control at } \\
\text { all }\end{array}$ & $\begin{array}{l}\text { A little } \\
\text { control }\end{array}$ & Neutral & $\begin{array}{l}\text { Considerable } \\
\text { control }\end{array}$ & Total control \\
\hline \multirow{4}{*}{ Intention } & I intend to stop dropping litter around the riverbank or into the river & Very unlikely & $\begin{array}{l}\text { Somewhat } \\
\text { unlikely }\end{array}$ & Neutral & Quite likely & Very likely \\
\hline & I will not defecate around the riverbank or into the river (even if I have done it in the past) & $\begin{array}{l}\text { Completely } \\
\text { disagree }\end{array}$ & $\begin{array}{l}\text { Somewhat } \\
\text { disagree }\end{array}$ & Neutral & $\begin{array}{l}\text { Somewhat } \\
\text { agree }\end{array}$ & $\begin{array}{l}\text { Completely } \\
\text { agree }\end{array}$ \\
\hline & $\begin{array}{l}\text { I will try not to wash my bicycle, tricycle, car, lorry or clothes around the riverbank or in the } \\
\text { river. }\end{array}$ & $\begin{array}{l}\text { Completely } \\
\text { disagree }\end{array}$ & $\begin{array}{l}\text { Somewhat } \\
\text { disagree }\end{array}$ & Neutral & $\begin{array}{l}\text { Somewhat } \\
\text { agree }\end{array}$ & $\begin{array}{l}\text { Completely } \\
\text { agree }\end{array}$ \\
\hline & I will not bath around the riverbank or in the river (using chemical soap). & Very unlikely & $\begin{array}{l}\text { Somewhat } \\
\text { unlikely }\end{array}$ & Neutral & Quite likely & Very likely \\
\hline
\end{tabular}

Notes: JHS = Junior High School; JSS = Junior Secondary School; SHS = Senior High School; SSS = Senior Secondary School. 
Table A2. Model fit indices.

\begin{tabular}{ccccccccc}
\hline $\mathbf{N}$ & $\chi^{2}$ & $\begin{array}{c}\text { Degrees of } \\
\text { Freedom } \\
\text { (df) }\end{array}$ & $p$-value & CFI & TLI & RMSEA & $\begin{array}{c}\text { 90\% conf. } \\
\text { int. } \\
\text { (RMSEA) }\end{array}$ & SRMR \\
\hline 510 & 55.3 & 225 & 0.000 & 0.907 & 0.962 & 0.035 & $0.019,0.08$ & 0.063 \\
\hline
\end{tabular}

\section{References}

1. United Nations Environment Programme. Towards a Pollution Free Planet Background Report; United Nations Environment Programme: Nairobi, Kenya, 2017.

2. Hutchins, M.G. What impact might mitigation of diffuse nitrate pollution have on river water quality in a rural catchment? J. Environ. Manag. 2012, 109, 19-26. [CrossRef] [PubMed]

3. OECD. Water Quality and Agriculture: Meeting the Policy Challenge. OECD Studies on Water; Organisation for Economic Co-Operation and Development: Paris, France, 2012.

4. OECD. Diffuse Pollution, Degraded Waters: Emerging Policy Solutions; OECD Publishing: Paris, France, 2017.

5. Blackstock, K.L.; Ingram, J.; Burton, R.; Brown, K.M.; Slee, B. Understanding and influencing behaviour change by farmers to improve water quality. Sci. Total Environ. 2010, 408, 5631-5638. [CrossRef] [PubMed]

6. Okumah, M.; Chapman, P.J.; Martin-Ortega, J.; Novo, P. Mitigating Agricultural Diffuse Pollution: Uncovering the Evidence Base of the Awareness-Behaviour-Water Quality Pathway. Water 2019, 11, 29. [CrossRef]

7. Barnes, A.P.; Willock, J.; Hall, C.; Toma, L. Farmer perspectives and practices regarding water pollution control programmes in Scotland. Agric. Water Manag. 2009, 96, 1715-1722. [CrossRef]

8. Inman, A.; Winter, M.; Wheeler, R.; Vrain, E.; Lovett, A.; Collins, A.; Jones, I.; Johnes, P.; Cleasby, W. An exploration of individual, social and material factors influencing water pollution mitigation behaviours within the farming community. Land Use Policy 2018, 70, 16-26. [CrossRef]

9. Macgregor, C.J.; Warren, C.R. Adopting sustainable farm management practices within a Nitrate Vulnerable Zone in Scotland: The view from the farm. Agric. Ecosyst. Environ. 2006, 113, 108-119. [CrossRef]

10. Vrain, E.; Lovett, A.; Noble, L.; Grant, F.; Blundell, P.; Clesby, W. Farmer Attitudes towards Diffuse Pollution Mitigation Measures in England: A Demonstration Test Catchments Report; Department for Environment, Food \& Rural Affairs: York, UK, 2014.

11. Vrain, E.; Lovett, A. The roles of farm advisors in the uptake of measures for the mitigation of diffuse water pollution. Land Use Policy 2016, 54, 413-422. [CrossRef]

12. Daxini, A.; O'Donoghue, C.; Ryan, M.; Buckley, C.; Barnes, A.P.; Daly, K. Which factors influence farmers' intentions to adopt nutrient management planning? J. Environ. Manag. 2018, 224, 350-360. [CrossRef]

13. Daxini, A.; Ryan, M.; O'Donoghue, C.; Barnes, A.P. Understanding farmers' intentions to follow a nutrient management plan using the theory of planned behaviour. Land Use Policy 2019, 85, 428-437. [CrossRef]

14. Daxini, A.; Ryan, M.; O’Donoghue, C.; Barnes, A.P.; Buckley, C. Using a typology to understand farmers' intentions towards following a nutrient management plan. Resour. Conserv. Recycl. 2019, 146, 280-290. [CrossRef]

15. Sieber, S.D. The integration of fieldwork and survey methods. Am. J. Sociol. 1973, 73, 1335-1359. [CrossRef]

16. United Nations. Global Sustainable Development Report 2016; Department of Economic and Social Affairs: New York, NY, USA, 2016.

17. Jackson, T. Motivating Sustainable Consumption: A Review of Evidence on Consumer Behaviour and Behavioural Change; Centre for Environmental Strategy, University of Surrey: Guildford, UK, 2005.

18. Ajzen, I. The theory of planned behavior. Organ. Behav. Hum. Decis. Process. 1991, 50, 179-211. [CrossRef]

19. Kollmuss, A.; Agyeman, J. Mind the gap: Why do people act environmentally and what are the barriers to pro-environmental behavior? Environ. Educ. Res. 2002, 8, 239-260. [CrossRef]

20. Ajzen, I.; Fishbein, M. Understanding Attitudes and Predicting Social Behavior; Prentice-Hall: Englewood Cliffs, NJ, USA, 1980.

21. Bamberg, S.; Möser, G. Twenty years after Hines, Hungerford, and Tomera: A new meta-analysis of psycho-social determinants of pro-environmental behaviour. J. Environ. Psychol. 2007, 27, 14-25. [CrossRef] 
22. Acheampong, R.A. Towards sustainable urban transportation in Ghana: Exploring adults' intention to adopt cycling to work using theory of planned behaviour and structural equation modelling. Transp. Dev. Econ. 2017, 3, 18. [CrossRef]

23. Wenchi Municipal Assembly. District Medium-Term Development Plan 2014; Wenchi Municipal Assembly: Wenchi, Ghana, 2014.

24. Abraham, E.M.; Martin, A.; Cofie, O.; Raschid-Sally, L. Perceptions, attitudes and behaviours toward urban surface water quality in Accra, Ghana. Manag. Environ. Qual. Int. J. 2016, 27, 491-506. [CrossRef]

25. Hayes, A.F. Introduction to Mediation, Moderation and Conditional Process Analysis; The Guildford Press: New York, NY, USA; London, UK, 2013.

26. Mciver, J.P.; Carmines, E.G. Unidimensional Scaling; Sage: Beverly Hills, CA, USA, 1981.

27. Cronbach, L.J. Coefficient alpha and the internal structure of tests. Psychometrika 1951, 16, 297-334. [CrossRef]

28. Fraenkel, J.R.; Wallen, N.E. How to Design and Evaluate Research in Education; McGraw-Hill: New York, NY, USA, 2000.

29. Okumah, M.; Martin-Ortega, J.; Novo, P. Effects of awareness on farmers' compliance with diffuse pollution mitigation measures: A conditional process modelling. Land Use Policy 2018, 76, 36-45. [CrossRef]

30. Lomax, R.G.; Schumacker, R.E. A Beginner's Guide to Structural Equation Modelling; Routledge: New York, NY, USA, 2012.

31. Bagozzi, R.P.; Yi, Y. Specification, evaluation, and interpretation of structural equation models. J. Acad. Mark. Sci. 2012, 40, 8-34. [CrossRef]

32. Rosseel, Y. The Lavaan Tutorial; Department of Data Analysis, Ghent University: Ghent, Belgium, 2017.

33. Rhemtulla, M.; Brosseau-Liard, P.É.; Savalei, V. When can categorical variables be treated as continuous? A comparison of robust continuous and categorical SEM estimation methods under suboptimal conditions. Psychol. Methods 2012, 17, 354-373. [CrossRef]

34. Kormos, C.; Gifford, R. The validity of self-report measures of proenvironmental behavior: A meta-analytic review. J. Environ. Psychol. 2014, 40, 359-371. [CrossRef]

35. Rathje, W.L. “Where's the Beef?" Red Meat and Reactivity. Am. Behav. Sci. 1984, 28, 71-91. [CrossRef]

36. Corral-Verdugo, V.C. Dual 'realities' of conservation behavior: Self-reports vs observations of re-use and recycling behavior. J. Environ. Psychol. 1997, 17, 135-145. [CrossRef]

37. Chao, Y.-L.; Lam, S.-P. Measuring responsible environmental behavior: Self-reported and other-reported measures and their differences in testing a behavioral model. Environ. Behav. 2011, 43, 53-71. [CrossRef]

38. Sheeran, P.; Conner, M.; Norman, P. Can the Theory of Planned Behavior Explain Patterns of Health Behavior Change? Health Psychol. 2001, 20, 12-19. [CrossRef] [PubMed]

39. Mostafa, M.M. Gender differences in Egyptian consumers' green purchase behaviour: The effects of environmental knowledge, concern and attitude. Int. J. Consum. Stud. 2007, 31, 220-229. [CrossRef]

40. Hunter, L.M.; Hatch, A.; Johnson, A. Cross-national gender variation in environmental behaviors. Soc. Sci. Q. 2004, 85, 677-694. [CrossRef]

41. Oppong, C.; Okali, C.; Houghton, B. Woman power: Retrograde steps in Ghana. Afr. Stud. Rev. 1975, 18, 71-84. [CrossRef]

42. Putnick, D.L.; Bornstein, M.H. Girls' and boys' labor and household chores in low- and middle-income countries. Monogr. Soc. Res. Child Dev. 2016, 81, 104-122. [CrossRef]

43. Franzen, A.; Vogl, D. Two decades of measuring environmental attitudes: A comparative analysis of 33 countries. Glob. Environ. Change 2013, 23, 1001-1008. [CrossRef]

44. Steg, L.; Vlek, C. Encouraging pro-environmental behaviour: An integrative review and research agenda. J. Environ. Psychol. 2009, 29, 309-317. [CrossRef]

45. Blake, J. Overcoming the 'value-action gap'in environmental policy: Tensions between national policy and local experience. Local Environ. 1999, 4, 257-278. [CrossRef]

46. Yeleliere, E.; Cobbina, S.; Duwiejuah, A. Review of Ghana's water resources: The quality and management with particular focus on freshwater resources. Appl. Water Sci. 2018, 8, 93. [CrossRef]

47. Ayer, H.W. Grass roots collective action: Agricultural opportunities. J. Agric. Resour. Econ. 1997, $22,1-11$.

48. Thomson, J.T. Ecological Deterioration: Local-Level Rule-Making and Enforcement Problems in Niger; Westview Press: Boulder, CO, USA, 1977.

49. Ostrom, E. Coping with tragedies of the commons. Ann. Rev. Political Sci. 1999, 2, 493-535. [CrossRef] 
50. Ostrom, E.; Burger, J.; Field, C.B.; Norgaard, R.B.; Policansky, D. Revisiting the commons: Local lessons, global challenges. Science 1999, 284, 278-282. [CrossRef] [PubMed]

51. Ostrom, E. Governing the Commons: The Evolution of Institutions for Collective Action; The Political Economy of Institutions and Decisions; Cambridge University Press: Cambridge, UK, 1990; p. 280.

(C) 2019 by the authors. Licensee MDPI, Basel, Switzerland. This article is an open access article distributed under the terms and conditions of the Creative Commons Attribution (CC BY) license (http://creativecommons.org/licenses/by/4.0/). 